\title{
EFFECT OF MICROSTRUCTURE ON FATIGUE PROPERTIES OF Al ALLOYS
}

\author{
AKIHIRO HIGASHI \\ Department of Mechanical Engineering, Kagoshima University, Kagoshima, 890-0065, Japan \\ k5227264@kadai.jp
}

\section{KOHJI KARIYA}

Department of Mechanical System Engineering, Dai-ichi University, Kirishima, 899-4395, Japan k-kariya@daiichi-koudai.ac.jp

\section{NORIO KAWAGOISHI}

Department of Mechanical Engineering, Kagoshima University, Kagoshima, 890-0065, Japan hiro@mech.kagoshima-u.ac.jp

\section{QIANG CHEN}

Department of Mechanical Engineering, Kochi National College of Technology, Nankoku, 783-8508, Japan qchen@me.kochi-ct.ac.jp

\section{MASAHIRO GOTO}

Department of Mechanical Engineering, Oita University, Oita, 870-1197, Japan masagoto@cc.oita-u.ac.jp

\begin{abstract}
Effects of a texture and atmospheric moisture on fatigue properties of an extruded bar and a drawn one of age-hardened $\mathrm{Al}$ alloy were investigated under rotating bending in relative humidity of $25 \%$ and $85 \%$. The extruded alloy had a marked texture of (111) plane, but the drawn one did not have a specified orientation. Fatigue strength was largely decreased by high humidity in both alloys. The decrease in fatigue strength was larger in the extruded alloy than in the drawn one. Macroscopic growth mode of a crack of the extruded alloy was a shear mode inclined $35^{\circ}$ to the specimen axis in high humidity, though those were a tensile mode in low humidity and in both humidity in the drawn alloy. The fracture surface yielded by the shear mode crack was occupied by many slip planes and voids and was (100) plane, though the fracture surface formed by the growth of a tensile mode crack was mainly covered with striations. The shear mode crack was related to the marked texture of the extruded $\mathrm{Al}$ alloy and promoted by high humidity.
\end{abstract}

Keywords: Age-hardened Al alloy; Extruded; Drawn; Humidity; Fracture mechanism.

\section{Introduction}

High strength Al alloys are attractive metals for reducing environment load because of their superior properties on specific strength, easy to recycle, and so on. However, the alloys are sensitive to humidity even though the humidity is mild for low and medium 
strength $\mathrm{Al}$ alloys ${ }^{1}$. Moreover, fatigue properties of $\mathrm{Al}$ alloys are different depending on microstructure $^{2}$. Therefore it is important to clarify the fatigue properties of high strength $\mathrm{Al}$ alloys in high humidity.

In the present study, in order to investigate effects of microstructure and humidity on the fatigue properties of high strength $\mathrm{Al}$ alloys, rotating bending fatigue tests were carried out using plain specimens of an extruded bar and an drawn one of age-hardened Al alloy $2017-\mathrm{T} 4$ in relative humidity of $25 \%$ and $85 \%$.

\section{Material and Experimental Procedure}

Material used was an extruded and a drawn bars of age-hardened Al alloy, 2017-T4. The chemical composition (mass\%) of the alloys were shown in Table 1.

Their mechanical properties are shown in Table 2. Static strength of the extruded alloy is a little higher than that of the drawn one.

Table 1. Chemical composition (mass $\%)$.

\begin{tabular}{|c|c|c|c|c|c|c|c|c|}
\hline & $\mathrm{Si}$ & $\mathrm{Fe}$ & $\mathrm{Cu}$ & $\mathrm{Mn}$ & $\mathrm{Mg}$ & $\mathrm{Cr}$ & $\mathrm{Zn}$ & $\mathrm{Ti}$ \\
\hline Extruded & 0.42 & 0.3 & 4.06 & 0.73 & 0.58 & 0.05 & 0.02 & 0.05 \\
\hline Drawn & 0.41 & 0.32 & 3.87 & 0.7 & 0.62 & 0.04 & 0.03 & 0.04 \\
\hline
\end{tabular}

Table 2. Mechanical properties.

\begin{tabular}{|c|c|c|c|c|}
\hline & $\sigma_{0.2} \mathrm{MPa}$ & $\sigma_{\mathrm{B}} \mathrm{MPa}$ & $\sigma_{\mathrm{T}} \mathrm{MPa}$ & $\phi \%$ \\
\hline Extruded & 350 & 471 & 638 & 32.4 \\
\hline Drawn & 303 & 464 & 718 & 43.7 \\
\hline
\end{tabular}

Fig. 1 shows shape and dimensions of specimen. Prior to fatigue testing, all of the specimens were slightly electro-polished by $40 \mu \mathrm{m}$ to secure the direct surface observation. The observation of fatigue damage and the measurement of crack length were conducted under a scanning electron microscope (SEM) or under an optical microscope by using the plastic-replica technique. Surface crack length, $\ell$, was measured in the circumferential direction of the specimen in both growth modes of a tensile and a shear. Fatigue tests were carried out using a rotating bending fatigue testing machine operated at $50 \mathrm{~Hz}$ repetition in relative humidity $(\mathrm{RH})$ of $25 \%$ and $85 \%$. The deviation of humidity was $\mathrm{RH} \pm 5 \%$ and the environmental temperature was not controlled, but it was $25 \pm 5^{\circ} \mathrm{C}$. Humidity tested was selected in considering that the effect of humidity on fatigue strength was largely changed around $60-70 \%{ }^{3,4}$.

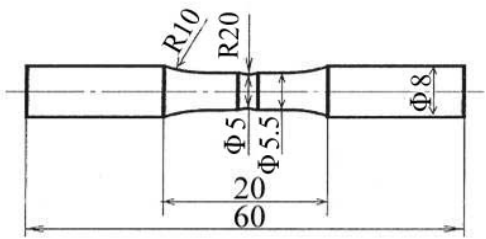

Fig.1. Shape and dimension of specimen (mm). 


\section{Experimental Results and Discussion}

Fig. 2 shows $S-N$ curves of both alloys in constant humidity of $25 \%$ and $85 \%$. In low humidity, fatigue strength of the extruded alloy is higher than that of the drawn one. Fatigue strength was decreased by high humidity, and the decrease by high humidity was larger in the extruded alloy than in the drawn one.

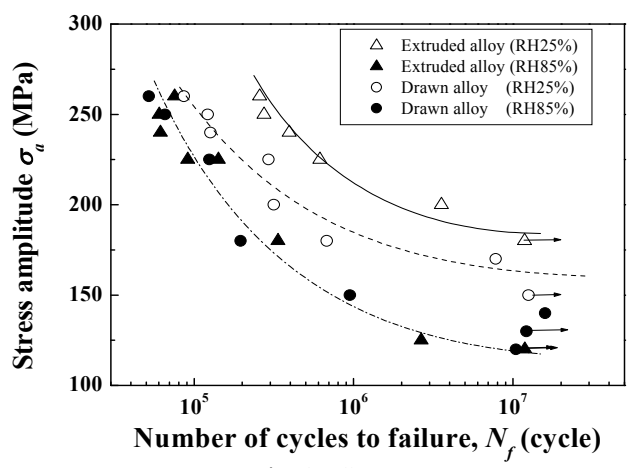

Fig. 2. $S$ - $N$ curves.

Fig. 3 shows crack growth curves of both alloys in both humidity. A crack initiated at the early stage of stress repetitions in both alloys and in both humidity. On the other hand, the growth behavior of a crack is different depending on the alloy and the humidity. That is, in low humidity, the retardation of the crack growth is confirmed in both alloys, and the retardation period is larger in the extruded alloy than in the drawn one. Moreover, the crack growth rate is higher in the drawn alloy than in the extruded one. On the other hand, in high humidity, the retardation of a crack growth is not confirmed. Moreover, the crack growth rate was hardly influenced by humidity in the drawn alloy, though it was accelerated in the extruded one. The crack growth rate is higher in the extruded alloy than in the drawn one inversely to the results in low humidity. From the results mentioned above, the reason for the decrease in fatigue strength by high humidity is the disappearance in the retardation of a crack growth in both alloys and the acceleration of a crack growth in the extruded alloy.

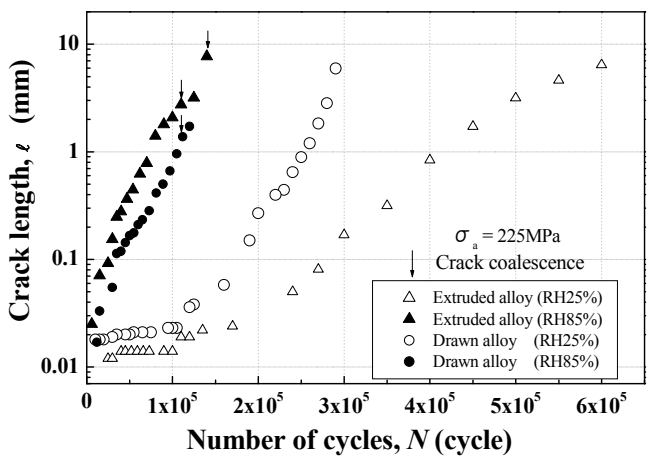

Fig. 3. Crack growth curves. 
Fig. 4 shows examples of crack morphologies in both alloys and humidity. In all the cases, a crack initiated at pits which were formed by electro-polishing for specimen preparation. It is difficult to evaluate the effect of humidity on the crack initiation from these results, though there are many reports that a crack initiation was accelerated by corrosion pits. However many cracks initiated at the corroded region and corrosion debris were observed in long life region beyond about $10^{6}$ cycles in high humidity as shown in Fig.5. Therefore, the acceleration of the initiation and the early growth process of a crack were mainly caused by anodic dissolution. The crack propagated in a shear mode macroscopically in the extruded alloy in high humidity, though the mode of a crack was a tensile in other cases, i.e. in the drawn alloy in both humidity and in the extruded one in low humidity. The growth direction of the shear mode crack is about $35^{\circ}$ to the specimen axis.

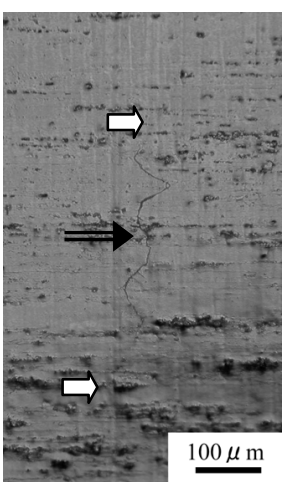

$N=2.0 \times 10^{5}$ cycles (a-1) In $25 \%$

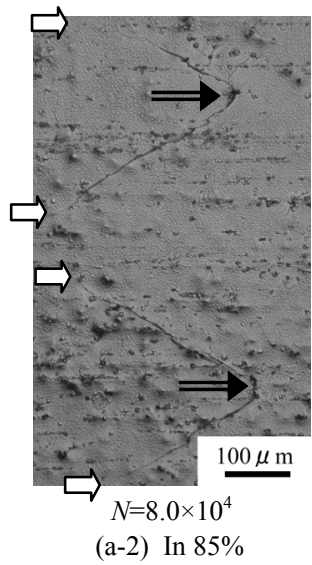

(a-2) In $85 \%$

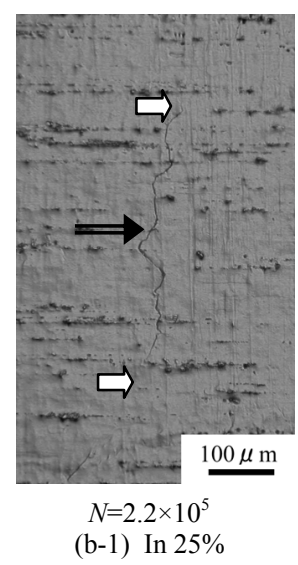

(b) Drawn Al alloy

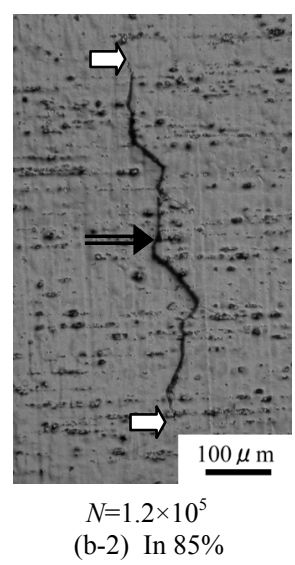

$N=1.2 \times 105$

(a) Extruded Al alloy

Fig. 4. Morphology of crack.

$\left(\sigma_{\mathrm{a}}=225 \mathrm{MPa}, \longleftrightarrow\right.$ :axial direction, $\Longrightarrow$ :crack initiation site, $\longrightarrow$ :crack tip )

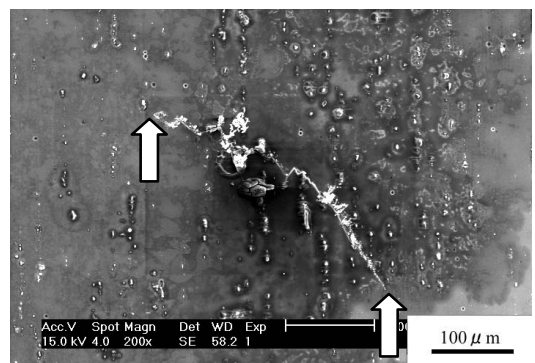

$\sigma_{\mathrm{a}}=125 \mathrm{MPa}, N_{\mathrm{f}}=2.6528 \times 10^{6}$ cycles

Fig. 5. Crack initiated at corroded region (Extruded $\mathrm{Al}$ alloy in $85 \%$, : crack tip).

Fig. 6 shows inverse pole figure at the cross section of the specimen. The extruded alloy has a marked texture of (111) plane, but any specified orientation are not confirmed in the drawn one. 
[001]

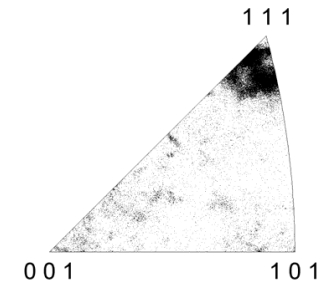

(a) Extruded Al alloy
[001]

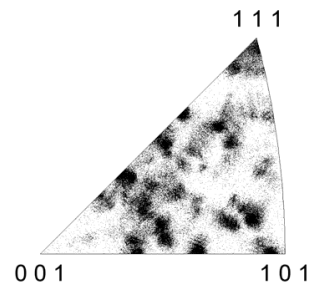

(b) Drawn Al alloy

Fig.6. Inverse pole figure.

Fig. 7 shows fracture surfaces in both alloys in both humidity. Striations were observed in most of fracture surfaces yielded by the growth of a tensile mode crack, while many slip planes and voids were observed where the shear mode crack propagated in the extruded alloy in high humidity. Therefore, change in growth mode of a crack from a tensile mode to a shear one may be a main reason for the higher growth rate of a crack in the extruded alloy in high humidity.

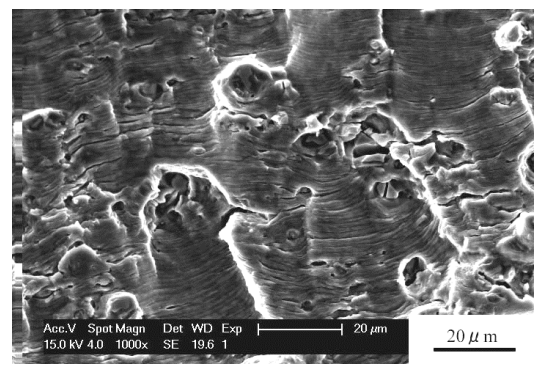

(a-1) In $25 \%, \sigma_{\mathrm{a}}=225 \mathrm{MPa}$

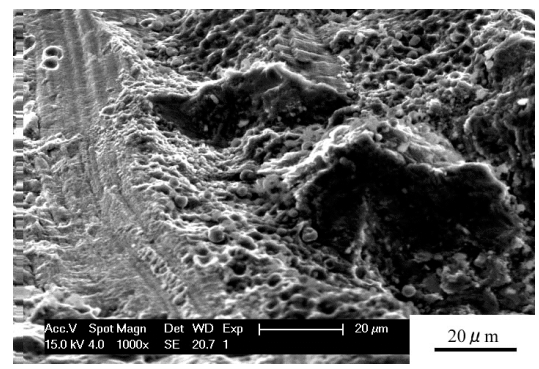

(a-2) In $85 \%, \sigma_{\mathrm{a}}=225 \mathrm{MPa}$

(a) Extruded Al alloy

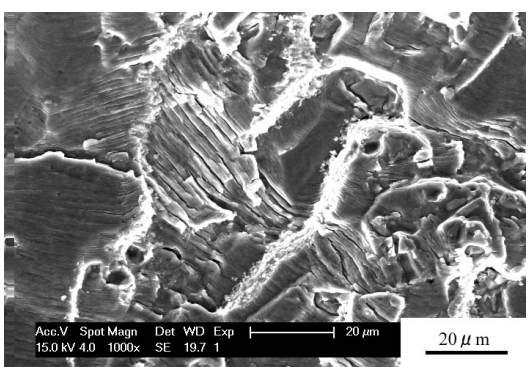

(b-1) In 25\%, $\sigma_{\mathrm{a}}=225 \mathrm{MPa}$

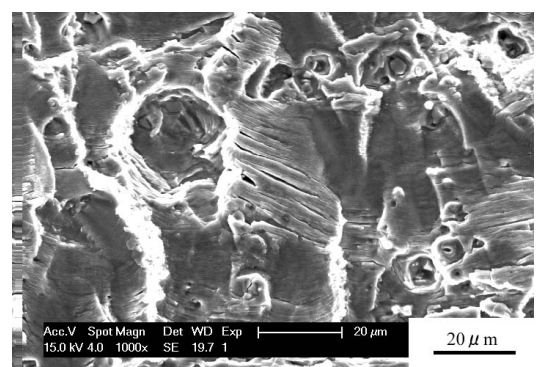

(b-2) In $85 \%, \sigma_{\mathrm{a}}=225 \mathrm{MPa}$

(b) Drawn Al alloy

Fig.7. Fracture surfaces. 
By observation of the orientation of crystalline at the fracture surface yielded by the shear mode crack in the extruded alloy, the fracture surface was a (100) plane. The angle composed by planes of (111) and (100) was about $54.7^{\circ}$, corresponding to the growth direction of a shear mode crack. This means that the shear mode crack of the extruded alloy may be related to its marked texture and promoted by water vapor.

\section{Conclusions}

In order to investigate effects of a texture and humidity on the fatigue properties of $\mathrm{Al}$ alloys, rotating bending fatigue tests were carried out using plain specimens of an extruded bar and a drawn one of age-hardened Al alloy 2017-T4 in relative humidity of $25 \%$ and $85 \%$. The extruded alloy had a marked texture of (111) plane, but a specified texture was not observed in the drawn one. Fatigue strength was largely decreased by high humidity in both alloys. The decrease in fatigue strength was larger in the extruded alloy than in the drawn one. The reason for the larger decrease in fatigue strength of extruded alloy was mainly caused by the acceleration of a crack growth due to the change of growth mode from a tensile direction to a shear one inclined about $35^{\circ}$ to the specimen axis. The fracture surface yielded by the shear mode crack was occupied by many slip planes and voids and was a (100) plane, though most of fracture surfaces yielded by the tensile mode crack were covered with striations. The shear mode crack related to the marked texture and was accelerated by humidity.

\section{References}

1. K. Endo and K. Komai. "Fatigue Crack Growth of Aluminum Alloy in Ultra-high Vacuum", Journal of the Society of Materials Science, Japan, 26, 281, 143 (1977).

2. H. Nisitani, N. Kawagoishi and M. Wakahara. "Comparison of Characteristics of Fatigue Properties in three kinds of Age-hardened Al Alloys", Transactions of the Japan Society of Mechanical Engineers, Series A, 51, 464, 1017 (2010).

3. N. Kawagoishi, T. Fukudome. Y. Nakamura, Y. Ohzono and M. Goto. "Propagation of Shear Mode Crack in Age-hardened and Extruded Al Alloy under Ultrasonic Loading”, Transactions of the Japan Society of Mechanical Engineers, Series A, 76, 767, 938 (2010).

4. N. Kawagoishi, T. Fukudome, K. Kariya, Q. Chen and M. Goto. "Fatigue Strength of Agehardened \& Extruded Al Alloy under High Humidity (Rotating Bending and Ultrasonic Loading)", Transactions of the Japan Society of Mechanical Engineers, Series A, 76, 772, 1651 (2010). 